\title{
Somatic growth rates for a hawksbill turtle population in coral reef habitat around Barbados
}

\author{
Barry H. Krueger ${ }^{1}$, Milani Y. Chaloupka ${ }^{2}$, Patrick A. Leighton ${ }^{3}$, Jennifer A. Dunn ${ }^{1,4}$, \\ Julia A. Horrocks ${ }^{1, *}$ \\ ${ }^{1}$ Department of Biological \& Chemical Sciences, University of the West Indies, Cave Hill, St Michael BB11000, Barbados \\ ${ }^{2}$ Ecological Modelling Services Pty Ltd, University of Queensland, PO Box 6150, St Lucia, Queensland 4067, Australia \\ ${ }^{3}$ Faculty of Veterinary Medicine, University of Montréal, 3200 Sicotte, CP 5000, Saint-Hyacinthe, Quebec J2S 7C6, Canada
}

${ }^{4}$ Present address: Duke University Marine Laboratory, 135 Marine Lab Road, Beaufort, North Carolina 28516, USA

\begin{abstract}
A generalized additive mixed modelling approach was used to investigate the somatic growth of hawksbill turtles Eretmochelys imbricata (23.7 to $80 \mathrm{~cm}$ curved carapace length [CCL]) on nearshore coral reef sites around Barbados at depths of 12 to $35 \mathrm{~m}$. The effects of body size, sex, sampling year, recapture interval and an indicator of foraging habitat quality on growth rates were investigated. The model accounted for about $60 \%$ of the variance in growth rates, but only mean size and sampling year were significant predictors. The growth rate function was nonmonotonic, with peak growth $\left(3.4 \mathrm{~cm} \mathrm{yr}^{-1}\right)$ occurring in turtles with a CCL between 30 and $35 \mathrm{~cm}$. The lower growth rates recorded for smaller turtles may reflect a period when sea turtles newly recruiting from pelagic to neritic habitats are adapting to a change in diet. The decline in growth rates with sampling year over the 10 yr study may reflect density-dependent effects on growth. Declining growth rates may prompt large juveniles to leave the Barbados foraging ground to settle elsewhere to grow to maturity.
\end{abstract}

KEY WORDS: Eretmochelys imbricata - Growth rate modelling - Barbados - Developmental habitat · Foraging ground $\cdot$ Density-dependent effect $\cdot$ Generalized additive mixed model

\section{INTRODUCTION}

The hawksbill turtle Eretmochelys imbricata is a circumtropical species found in the Atlantic, Indian, and Pacific Oceans (Witzell 1983). In the Caribbean, after an initial pelagic post-hatchling phase of unknown duration, juveniles of 20 to $25 \mathrm{~cm}$ carapace length settle in nearshore coral reef habitats for periods lasting several years (Boulon 1994, Diez \& van Dam 2002). Region-wide, individuals are reported to feed primarily on reef-associated sponges, as well as corallimorpharians and zoanthids (Meylan 1988, Anderes \& Uchida 1994, van Dam \& Diez 1997, Léon \& Bjorndal 2002, Blumenthal et al. 2009a). As large-sized spongivores, hawksbills are likely to be an important influence on reef community structure (Hill 1998, León \& Bjorndal 2002, Blumenthal et al. 2009a).

${ }^{*}$ Corresponding author. Email: julia.horrocks@cavehill.uwi.edu
Hawksbills have been heavily exploited for their shell, meat, and eggs, resulting in current populations being remnants of former abundances in most Caribbean territories (Mortimer \& Donnelly 2007). The species is currently listed as 'critically endangered' in the International Union for Conservation of Nature (IUCN) Red Book of Threatened Species (IUCN 2010). The marked decline in live hard coral cover and of structural complexity of coral reefs documented over recent decades (Mora 2008, Alvarez-Filip et al. 2009) and the potential role that hawksbills may play in coral reef community dynamics increase the importance of population recovery of this species. Despite this importance, much of the life history and ecology of hawksbills - knowledge of which is needed to guide conservation and management-remains poorly understood. 
Measurement of somatic growth rates of juvenile sea turtles is a prerequisite for assessment of life-stage durations and age to maturity, and has inevitably focused on the more accessible benthic feeding-phase size classes (but see Bjorndal et al. 2003). To date, modelling of growth has focused on loggerheads (e.g. Bjorndal \& Bolten 1988a, Bjorndal et al. 1994, 2003, Chaloupka et al. 2004, Braun-McNeill et al. 2008) and green turtles (e.g. Bjorndal \& Bolten 1988b, Limpus \& Chaloupka 1997, Bjorndal et al. 2000, Balazs \& Chaloupka 2004, Kubis et al. 2009). Growth rate data for juvenile hawksbills have been reported from the US Virgin Islands (Boulon 1994), the Dominican Republic (León \& Diez 1999), Puerto Rico (Diez \& van Dam 2002), the Bahamas (Bjorndal \& Bolten 2010), and the Cayman Islands (Blumenthal et al. 2009a) in the Caribbean region, as well as from Australia (Chaloupka \& Limpus 1997, Whiting \& Guinea 1998) and Aldabra (Indian Ocean) (Mortimer et al. 2003). Interpretation of growth patterns in several of these studies has, however, been hampered by small sample sizes and short recapture intervals (i.e. $<1$ yr).

A number of factors affect growth rates of juvenile green and loggerhead turtles. Variability has been attributed to habitat type (Balazs \& Chaloupka 2004, Kubis et al. 2009, Bjorndal \& Bolten 2010), population density (Bjorndal et al. 2000, Balazs \& Chaloupka 2004, Kubis et al. 2009), and water temperature (Gibbons et al. 1981), as well as to stock-specific (Seminoff et al. 2002), age-specific (Bjorndal et al. 2003) and sexspecific factors (Chaloupka et al. 2004). León \& Diez (1999) and Diez \& van Dam (2002) found differences in growth rates of juvenile hawksbills in different habitats, attributing these largely to variation in preferredprey abundance. These findings suggest that, as with other species (e.g. green turtles) (Kubis et al. 2009), mean growth rates of hawksbills should be applied with caution across sites, even within the Caribbean region. Potential density-dependent effects on growth rates are particularly important to ascertain for management of recovering populations (Bjorndal et al. 2000, Kubis et al. 2009).

The hawksbills foraging around Barbados are a mixed genetic stock originating both within and outside of the Wider Caribbean (Abreu-Grobois et al. 2006) and comprise individuals ranging in size from 23.7 to $80 \mathrm{~cm}$ curved carapace length (CCL). Previous study sites from which hawksbill growth rates have been reported have tended to be shallow (up to $20 \mathrm{~m}$ ) (e.g. Blumenthal et al. 2009b, Bjorndal \& Bolten 2010, but see Diez \& van Dam 2002). In this study, we present data on somatic growth rates obtained from a longitudinal mark-recapture study of juvenile hawksbills on a neritic foraging ground (12 to $35 \mathrm{~m}$ ) on coral reef habitat off the west coast of Barbados, West Indies. We evaluate the form of the somatic growth rate function using a generalized additive mixed modelling (GAMM) approach, and for the first time for hawksbills, we include an indicator of food abundance as a variable that may affect growth rates. Finally, we compare the mean growth functions in our study with those previously reported.

\section{MATERIALS AND METHODS}

Study site. Barbados $\left(13^{\circ} 09^{\prime} 39^{\prime \prime} \mathrm{N}, 59^{\circ} 33^{\prime} 08^{\prime \prime} \mathrm{W}\right)$ is a small island $\left(430 \mathrm{~km}^{2}\right)$ in the south-eastern Caribbean, approximately $200 \mathrm{~km}$ to the east of the Lesser Antilles island chain. The island is composed of uplifted fossil corals and is surrounded by a 1 to $3 \mathrm{~km}$ wide shelf with different forms of living coral reef habitats. The west coast is characterized by fringing reefs along the shoreline and an almost continuous bank reef that runs parallel to the west coast for $\sim 22 \mathrm{~km}$ and lies $\sim 1 \mathrm{~km}$ offshore.

In-water hawksbill surveys have been conducted on foraging sites on the west coast reef systems since July 1998. Most dive effort has focused on 10 sites on the bank reef and 3 sites on the outer edge of the fringing reefs (Fig. 1). At each site, the number of colonies (>10 cm diameter) of a preferred hawksbill prey sponge species Sidonops neptuni (formerly Geodia neptuni) were counted along 15 belt transects $(5 \times$ $20 \mathrm{~m}$ ) that sampled each reef site from its outer to inner edge. S. neptuni was determined as a preferred sponge based on the quantity of feeding scars left by foraging turtles. Although large colonies may be difficult to access for smaller turtles because of the sponge's thick cortex, small juvenile turtles may access the interior through the bites made by larger juveniles, and our observations indicate that smaller individuals can readily access smaller sponge colonies. Encrusting forms of the sponge are very rare in Barbados, allowing the count of all $S$. neptuni colonies ( $>10 \mathrm{~cm}$ diameter) to be an accurate assessment of the quantity of this particular forage item at our study sites. All but one of the sites had $<2$ S. neptuni colonies per $100 \mathrm{~m}^{2}$, and these were referred to as Low Sponge sites. One site had more than twice as many colonies as the other sites (>5 S. neptuni colonies per $100 \mathrm{~m}^{2}$ ) and this was referred to as the High Sponge site. Turtles were significantly larger at the High Sponge site than at the Low Sponge sites (mean CCL 48.6 and $43.8 \mathrm{~cm}$, respectively; $t=4.28, \mathrm{p}<0.01$ ). The density of $S$. neptuni (no. colonies $\mathrm{m}^{-2}$ ) was used as an indicator of foraging habitat quality at our sites, as no information is available on how resource requirements of hawksbills may change with size or age, or how the digestibility of sponges may change with size of colonies. 


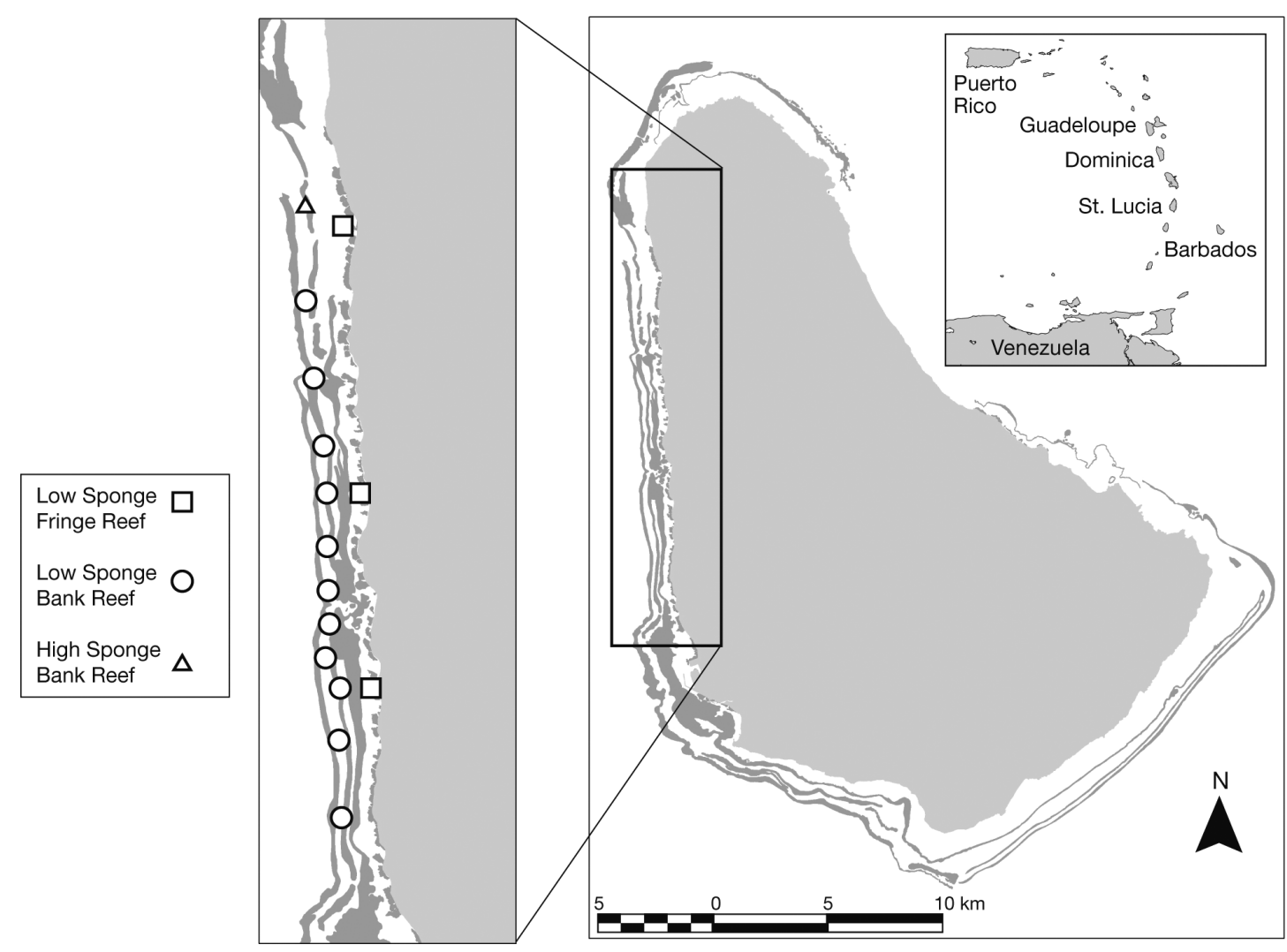

Fig. 1. Barbados with insets showing its position in the Eastern Caribbean and the locations of study sites on the west coast reef system. Base map: Coastal Zone Management Unit (2002)

Data collection. Turtles were hand caught by SCUBA divers and brought aboard an anchored research vessel where standard morphometric data were collected. Surveys were typically conducted twice per week (4 dives) during all months of the year, but most were carried out between May and December. The survey team generally consisted of 3 to 4 divers, and 2 individuals were primarily responsible for collecting the measurement data.

The CCL of each captured individual was measured with a flexible fiberglass tape measure. Turtles were measured to the nearest $0.1 \mathrm{~cm}$. Note was made of which posterior marginal scute (left or right) was used in the initial CCL measurement; subsequent measurements on that individual were then made to the same scute. Tape measures were frequently checked for accuracy and measurement error was reduced by regularly testing the precision of data collectors at measuring the same carapaces. All turtles were weighed with a hand-held digital spring scale to the nearest $0.1 \mathrm{~kg}$. At first capture, turtles were double-tagged with uniquely numbered Inconel flipper tags (National Band \& Tag Company) in the first proximal scale of each foreflipper (Bolten 1999). During subsequent captures, if tags were growing out or looked as though they would soon fall out, 1 or 2 additional tags were placed in the second proximal scale(s). Tag loss is considered to be negligible in this study (17 of $877=$ $1.94 \%$ ). A sub-set of turtles was also sexed internally by laparoscopic examination using a $2.9 \mathrm{~mm}$ diameter Karl Storz endoscope with separate light source (see Limpus \& Reed 1985). Sex was therefore assigned as male, female, or undetermined in the analyses that follow, based on the presence of either ovaries or testes. All captured turtles were released at the site of capture within $1 \mathrm{~h}$ of being caught.

Data set. The data set comprised 504 growth records for 290 different hawksbill turtles tagged at depths of 12 to $35 \mathrm{~m}$ on the west coast reef system of Barbados over a 10 yr study period (July 1998 to November 2008). The time intervals between recaptures (sampling intervals) ranged from 7 to $2590 \mathrm{~d}$, but only capture intervals of $>330 \mathrm{~d}$ were included in the growth analysis (for discussion of minimum capture intervals see Bjorndal et al. 2000, Seminoff et al. 2002). Recapture intervals therefore ranged from 330 to $2590 \mathrm{~d}$ $($ mean $\pm \mathrm{SD}=731.44 \pm 378.01 \mathrm{~d}, \mathrm{~N}=504)$. The data set included 153 female, 133 male, and 218 sexundetermined growth intervals for hawksbill turtles with CCL from 23.7 to $80.0 \mathrm{~cm}$. Movement between 
sites was only recorded for 1 individual for which growth rates were recorded, and this individual was not included in the analysis. Individuals over $80 \mathrm{~cm}$ CCL were also excluded from the modeling analyses, as they were presumed to be migratory breeders rather than residents (Horrocks et al. 2001).

Statistical modeling approach. Factors and/or covariates affecting hawksbill somatic growth rates were estimated using generalized additive modelling (GAM). GAM allows (1) flexible specification of the error and link functions and (2) arbitrary specification of the functional form for each continuous predictor or covariate included in the regression model (Hastie \& Tibshirani 1993). Importantly, GAMs can be readily extended to account for random or mixed effects (generalized additive mixed models [GAMMs]) (Fahrmeir \& Lang 2001, Wood 2006) for studies that involve multiple measurements on the same sampling unit, e.g. repeated measurements for growth rate of turtles recaptured more than once.

The GAMMs applied here were fitted using (1) thin plate regression splines to model any non-linear covariate effects (i.e. mean carapace size, mean sampling year, growth interval), (2) a log link and constant variance consistent with the particular properties of this data set, (3) quasi-likelihood error structure, and (4) turtle-specific heterogeneity as a random effect. Growth interval was included in the model as a covariate to account for possible bias caused by the discrepancy in growth intervals (330 to $2590 \mathrm{~d}$ ). The year effect is a potential source of growth variability due to environmental factors which change from year to year. It must be included in the model, even though it is inevitably confounded with unknown cohort effects when the ages of turtles are unknown, as in this study. Some of the other unknowns which could not be included in the model were growth rate variation attributable to genetic variation between different stocks recruiting to the foraging ground and differences in parasite loads of newly recruiting individuals.

Only main-effects GAMMs were fitted here, but interaction terms such as habitat-specific growth rate functions can be accommodated in a GAM(M) framework using the varying coefficient (VC) approach proposed by Hastie \& Tibshirani (1993). This VCGAMM approach was explored with our data, but fitting sex- or habitat-specific growth rate functions did not improve the explanatory power of the models significantly (likelihood ratio test, $\mathrm{p}>0.05$ in all cases), and models failed to converge for more complex interactions.

The importance of explicitly accounting for turtlespecific hetereogeneity using a GAMM was evaluated using the following approach: (1) fit a GAM instead of a GAMM to the same data set and extract the deviance residuals; (2) fit a linear mixed-effects model to the residuals using a constant parameter only model with experimental run as the random effect; (3) fit a linear fixed-effects model to the residuals using a constant parameter only model; and (4) compare the fit of the 2 linear models using Akaike's Information Criterion (AIC) or a likelihood ratio test (see Wood 2006).

All the GAMM or related models were fitted in R (Ihaka \& Gentleman 1996, R Development Core Team 2008) using the 'mgcv' package (Wood 2006). Linear mixed-effects models were fitted using the 'lme()' function in the 'nlme' $\mathrm{R}$ package (Pinheiro \& Bates 2000), while linear fixed-effects models were fitted using the ' $\operatorname{lm}($ )' R function (Pinheiro \& Bates 2000).

\section{RESULTS}

The growth rate of individual juvenile hawksbill turtles on Barbados reefs ranged from -0.31 to $7.19 \mathrm{~cm} \mathrm{yr}^{-1}$, with a mean of $2.03 \mathrm{~cm} \mathrm{yr}^{-1}\left(\mathrm{SD}=1.27 \mathrm{~cm} \mathrm{yr}^{-1}, \mathrm{~N}=504\right)$. Our GAMM included growth rate as the response variable and 5 potential predictors of growth (mean size, mean sampling year, growth interval, sex, and sponge density; Table 1, Fig. 2). The model was a good fit to the data with no aberrant residual behaviour and accounted for $58 \%$ of the growth rate variance. The GAMM fit our data significantly better than a GAM that did not account for experimental run-specific heterogeneity (GAMM $\mathrm{AIC}=1163.58$ compared to GAM AIC $=1217.66$, likelihood ratio test $\chi_{0.05}^{2}=56.07, \mathrm{df}=1, \mathrm{p}<0.0001$ ).

Table 1. Eretmochelys imbricata. Parametric and non-parametric terms of a generalized additive mixed model (GAMM) used to model growth rate of hawksbill sea turtles in Barbados. SE: standard error; df: estimated degrees of freedom for smooth term $(1=$ linear $)$, CCL: curved carapace length

\begin{tabular}{|lrrrr|}
\hline Term & Estimate & SE & $t$ & $\mathrm{p}$ \\
\hline Parametric & & & & \\
Intercept & 1.085 & 0.030 & 36.507 & $<0.001$ \\
Sex (male vs. female) & -0.004 & 0.040 & -0.103 & 0.918 \\
Sex (undetermined vs. female) & -0.051 & 0.038 & -1.322 & 0.187 \\
& & & & \\
& & df & & $\mathrm{p}$ \\
\hline Non-parametric smooth & & & & \\
Mean turtle size (CCL) (cm) & & 6.316 & 78.128 & $<0.001$ \\
Mean sampling year & 4.185 & 17.694 & $<0.001$ \\
Growth interval (d) & 1.000 & 0.357 & 0.551 \\
Sponge density (no. m ${ }^{-2}$ ) & & 1.000 & 0.250 & 0.875 \\
\hline
\end{tabular}



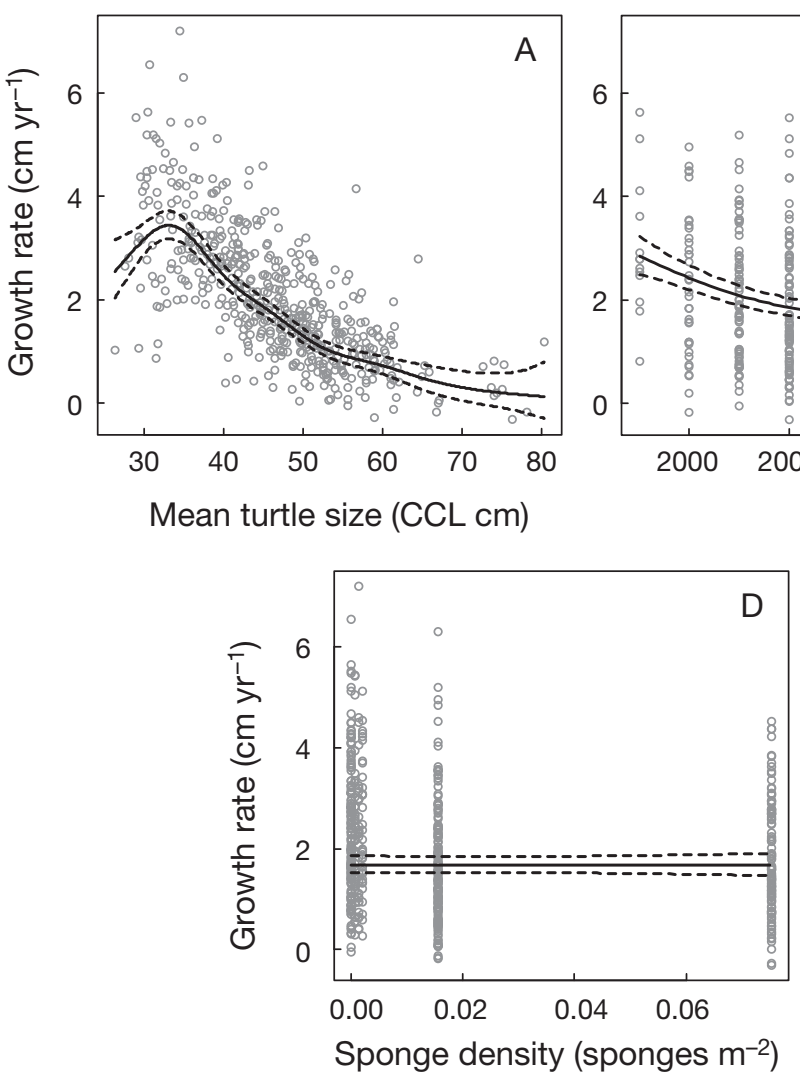
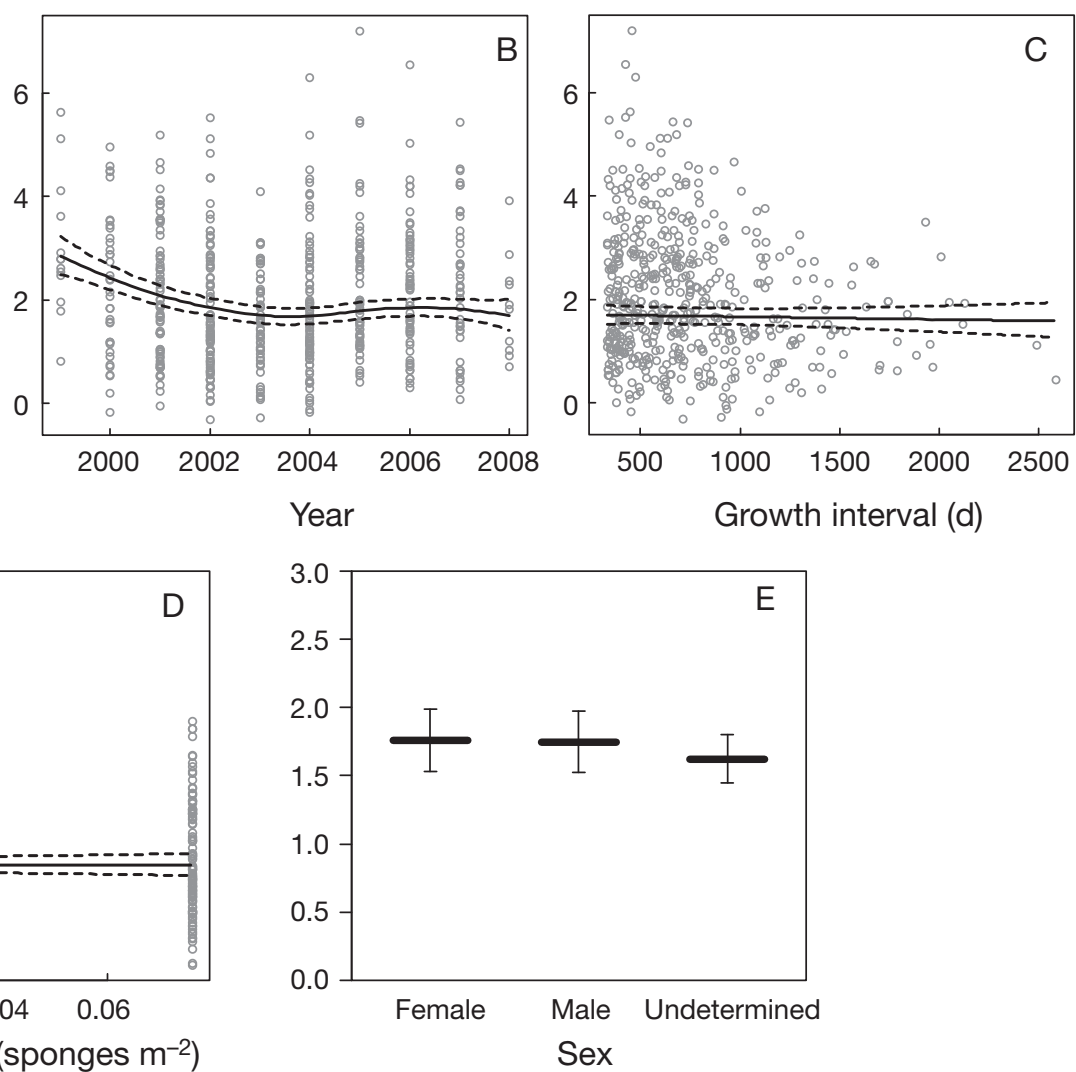

Fig. 2. Eretmochelys imbricata. Predictors in the fitted generalized additive mixed model (GAMM) of growth rate for hawksbill sea turtles in Barbados. (A) Mean turtle size (CCL: curved carapace length), (B) mean sampling year, (C) growth interval, (D) sponge density, and (E) sex. Dashed lines (A-D) and error bars (E) represent the $95 \%$ confidence interval for fitted values

The GAMM analysis suggested that juvenile growth rates were dependent on both size and year (Table 1), although age and cohort effects could not be separated. The shape of the growth function with mean size was nonmonotonic, with growth rate highest in the 30 to $35 \mathrm{~cm}$ size class. Growth interval, sex, and sponge density were not significant predictors of growth rates (Table 1). The remaining variability suggests that factors other than those investigated, e.g. genetic stock, may be affecting growth rates.

\section{DISCUSSION}

The study population of hawksbills foraging around Barbados in the south-eastern Caribbean is composed largely of juveniles between 23.7 and $65 \mathrm{~cm}$ CCL. Based on the largest sample size for juvenile hawksbill turtles to date (504 growth intervals of $>330 \mathrm{~d}$ ), Barbados hawksbills grow at a mean rate of $2.03 \mathrm{~cm} \mathrm{yr}^{-1}$, with a peak of $3.4 \mathrm{~cm} \mathrm{yr}^{-1}$ at 30 to $35 \mathrm{~cm}$ CCL. These growth rates are considerably lower than those previously published for the Caribbean region (Boulon 1994, León \& Diez 1999, Diez \& van Dam 2002, Blu- menthal et al. 2009a, Bjorndal \& Bolten 2010), and more similar to the lower growth rates recorded for the southern Great Barrier Reef in Australia (Chaloupka \& Limpus 1997). However, the highly significant effect of sex on growth rates in Australian hawksbills (with females growing faster than males) reported in the only other study to investigate the effect of sex on hawksbill growth (Chaloupka \& Limpus 1997), was not detected in our study. Sex-specific differences in growth rates of juvenile green turtles in the Bahamas, a Western Atlantic/Caribbean study site, have also been reported, but the pattern was the reverse, with males growing significantly faster than females (Bjorndal et al. 2000).

The size-specific growth rate function for juvenile hawksbills around Barbados was nonmonotonic as has been shown previously for hawksbills in Puerto Rico (Diez \& van Dam 2002), Australia (Chaloupka \& Limpus 1997), and Aldabra (Mortimer et al. 2003). As found in Puerto Rican hawksbills, the growth spurt peak of Barbados hawksbills occurred at a much smaller size $(33 \mathrm{~cm}$ CCL in our study, $35 \mathrm{~cm}$ standard carapace length [SCL] in Monito, Puerto Rico; Diez \& van Dam 2002) than the 55 to $60 \mathrm{~cm}$ CCL in Australia 
(Chaloupka \& Limpus 1997) and 60 to $70 \mathrm{~cm}$ CCL in Aldabra (Mortimer et al. 2003). The slower growth rates of Barbados hawksbills at smaller sizes may reflect a period when juvenile sea turtles newly recruiting from pelagic to neritic habitats are adapting to their new diet (Bjorndal \& Bolten 2010; see also Kubis et al. 2009 for green turtles) and perhaps learning to distinguish more palatable species of sponges. This slower growth period may be swiftly followed by a compensatory growth phase of peak growth in the 30 to $35 \mathrm{~cm}$ size class (Fig. 2A). Our study also supports the observation that Caribbean hawksbills recruit to the foraging grounds at a smaller size than Australian hawksbills (Diez \& van Dam 2002, Bjorndal \& Bolten 2010), suggesting that differences in the form of growth may be indicative of as yet undetermined genetic and/or environmental effects on hawksbill growth in different oceanic basins.

As the growth peak occurs at a small size in both Barbados and Puerto Rico, an absence of these size classes of hawksbills in the Bahamas study may have led to the conclusion that growth was a monotonic decreasing function of size (Bjorndal \& Bolten 2010). Green turtles also recruit to Bahamian foraging grounds at small sizes (25 to $35 \mathrm{~cm} \mathrm{SCL)} \mathrm{(Bjorndal} \mathrm{et} \mathrm{al.}$ 2000), and although the full range of juvenile green turtles was represented in their study, Bjorndal et al. (2000) again did not detect an early compensatory growth spurt, but instead observed a monotonic decline in growth rates. This may suggest speciesspecific differences between green turtles and hawksbills in the Western Atlantic/Caribbean in the adjustment to a new diet and/or greater availability of food choices for newly recruiting herbivorous species than spongivorous species. Kubis et al. (2009) have recently reported nonmonotonic growth for juvenile green turtles at sites with very different ecological characteristics and presumably also different food choices along the east coast of Florida, where they reported growth peaks occurring at 35 to $55 \mathrm{~cm}$ SCL depending on the site.

Differences in hawksbill growth rates found in previous studies have been attributed to variation in environmental characteristics (e.g. availability of preferred sponges: Diez \& van Dam 2002, León \& Diez 1999; water temperature: Republic of Cuba report to the Convention on International Trade in Endangered Species in Diez \& van Dam 2002). At sites around Barbados, there was no significant difference in growth rates of juveniles with sponge density in our study, although growth rates were lower than those reported in previous studies. Body condition index (CI) calculated using Fulton's $K$ (mass $\div \mathrm{SCL}^{3}$; Ricker 1975), multiplied by a scaling factor of $10^{4}$ to bring it close to 1 , provided an indication of sea turtle health and fit- ness. CI was 1.17 for turtles at the High Sponge site and 1.18 for those at Low Sponge sites, i.e. both values were at the lower end of the range of CI values obtained for hawksbills elsewhere in the region (Diez \& van Dam 2002, Blumenthal et al. 2009a, Bjorndal \& Bolten 2010) and were most similar to values obtained for hawksbills occupying peripheral seagrass habitats in the Bahamas (Bjorndal \& Bolten 2010). Low growth rates combined with low $\mathrm{CI}$ values may suggest that Barbados, although one of the first land masses encountered by pelagic hawksbills following an early phase of trans-Atlantic drifting, may be sub-optimal foraging habitat for hawksbills. The very slow, incremental growth after $60 \mathrm{~cm}$ CCL (Fig. 2) suggests that hawksbills would take several decades to grow to the size of the smallest females observed nesting in Barbados (76.2 cm CCL) (Beggs et al. 2007) if they remained on the Barbados foraging ground. However, our observations show little evidence of turtles larger than $60 \mathrm{~cm}$ CCL foraging around Barbados, at least at the depths regularly surveyed in our study (12 to $35 \mathrm{~m}$ ). Sightings or captures of individuals larger than $60 \mathrm{~cm}$ CCL typically only occur during the breeding season, when breeding adults migrate from foraging grounds around other countries to nest in Barbados (Horrocks et al. 2001). Larger hawksbills are capable of foraging at greater depths and may be utilizing deeper water sites (e.g. Horrocks et al. 2001, Blumenthal et al. 2009b), but the possibility that adults would only be seen foraging in shallower waters during the breeding season seems unlikely. Moreover, several tagged adult females have been observed occupying the same reef crevices in consecutive breeding seasons, but have not been observed between breeding seasons. For these reasons, we are confident that adults do not typically forage on reefs around Barbados, but instead leave after the breeding season and return to foraging grounds elsewhere (Horrocks et al. 2001).

The recent tag recovery of a hawksbill tagged as a $45 \mathrm{~cm}$ SCL juvenile in the Bahamas and seen nesting $9.4 \mathrm{yr}$ later (Bjorndal et al. 2008) indicates a much shorter time to sexual maturity than our growth rate data would suggest. Interestingly, the recovery concerned a juvenile that was tagged initially on a foraging ground that has reported high growth rates (Bjorndal \& Bolten 2010). By contrast, the lower growth rates and condition indices seen in Barbados hawksbills, suggests that foraging ground quality off Barbados is sub-optimal for large juveniles to reach sexual maturity. Juvenile turtles may instead move away from Barbados and mature on more productive foraging grounds elsewhere in the Wider Caribbean. A relative scarcity of sightings of subadult-sized turtles (60 to $75 \mathrm{~cm} \mathrm{CCL}$ ) reported from the foraging grounds of the region in general, however, suggests that this transi- 
tion phase from sub-adult to adulthood might be passed through relatively quickly once a suitable foraging ground is reached.

Sampling year had a significant effect on growth rates on the Barbados foraging ground, with growth rates declining by about $1 \mathrm{~cm} \mathrm{yr}^{-1}$ between 1998 and 2004, and only increasing slightly before leveling off in 2006. Bjorndal et al. (2000) and Kubis et al. (2009) also found sampling year effects in their studies of Western Atlantic/Caribbean juvenile green turtles, attributing their results to density-dependent effects on growth rates. The abundance of juvenile hawksbills around Barbados was higher at the end of our study than at the onset (B. H. Krueger unpubl. data) and may have caused negative density-dependent effects on growth rates. The effect of increasing turtle abundance may have been exacerbated by several coral bleaching episodes at our study sites on the west coast bank reef, correlated with unusually high seawater temperatures (e.g. Oxenford et al. 2008), which may have further reduced habitat quality for hawksbills in their primary foraging habitat. These findings support the suggestion that peripheral hawksbill foraging habitat in seagrass pastures may become increasingly important in the region (Bjorndal \& Bolten 2010), and emphasize the need to include protection of both coral reefs and seagrass in efforts to ensure long-term recovery of hawksbill turtles.

Acknowledgements. We are deeply grateful to the following: Hightide Watersports, W. Hewitt, G. Smith, and M. Norsworthy for providing their dive boat, diving equipment and cylinder fills. We also thank staff of Hightide Watersports including boat skipper V. Addison, diving instructors E. Blackman, J. Edwards, and many others. We thank L. Vermeer for providing the encouragement to commence the project and all Barbados Sea Turtle Project volunteers, especially V. Houmeau, A. Stevens, and A. Luque. We are grateful to J. Miller for training in laparoscopy techniques. C. Wabnitz kindly provided comments on an earlier draft of the manuscript. All research was carried out under permits from the Fisheries Division of the Ministry of Agriculture and Rural Development, Government of Barbados. Funding was provided by the University of the West Indies Office of Research and the Australian High Commission, Barbados.

\section{LITERATURE CITED}

Abreu-Grobois A, Horrocks JA, Krueger B, Formia A, Browne D, Beggs J (2006) Hawksbill turtles foraging around Barbados, West Indies, originate from rookeries both within and outside of the Wider Caribbean. In: Frick M, Panagopoulou A, Rees AF, Williams K (eds) Book of Abstracts. 26th Annual Symposium on Sea Turtle Biology and Conservation. International Sea Turtle Society, Crete, p 180

Alvarez-Filip L, Dulvy NK, Gill JA, Cote IM, Watkinson AR (2009) Flattening of Caribbean coral reefs: region-wide declines in architectural complexity. Proc Biol Sci 276: 3019-3025

Anderes BL, Uchida I (1994) Study of hawksbill turtle
(Eretmochelys imbricata) stomach contents in Cuban waters. In: Study of the hawksbill turtle in Cuba (I). Ministry of Fishing Industry, La Habana, p 27-40

Balazs G, Chaloupka M (2004) Spatial and temporal variability in somatic growth of green sea turtles (Chelonia mydas) resident within the Hawaiian Archipelago. Mar Biol 145: 1043-1059

Beggs J, Horrocks JA, Krueger B (2007) Increase in hawksbill sea turtle Eretmochelys imbricata nesting in Barbados, West Indies. Endang Species Res 3:159-168

Bjorndal KA, Bolten AB (1988a) Growth rates of juvenile loggerheads, Caretta caretta, in the southern Bahamas. J Herpetol 22:480-482

Bjorndal KA, Bolten AB (1988b) Growth rates of immature green turtles, Chelonia mydas, on feeding grounds in the southern Bahamas. Copeia 1988:555-564

Bjorndal KA, Bolten AB (2010) Hawksbill sea turtles in seagrass pastures: success in a peripheral habitat. Mar Biol 157:135-145

Bjorndal KA, Bolten AB, Gordon J, Caminas J (1994) Natural history notes: Caretta caretta (loggerhead). Growth and pelagic movement. Herpetol Rev 25:23-24

Bjorndal KA, Bolten AB, Chaloupka MY (2000) Green turtle somatic growth model: evidence for density-dependence. Ecol Appl 10:269-282

Bjorndal KA, Bolten AB, Dellinger T, Delgado C, Martins HR (2003) Compensatory growth in oceanic loggerhead sea turtles: response to a stochastic environment. Ecology 84: 1237-1249

Bjorndal KA, Clovis T, Reich KJ, Alkins G, Eliazar PJ, Bolten AB (2008) Juvenile hawksbill tagged in the Bahamas nests in Tobago. Mar Turt Newsl 122:10-11

Blumenthal JM, Austin TJ, Bell CDL, Bothwell JB and others (2009a) Ecology of hawksbill turtles, Eretmochelys imbricata, on a western Caribbean foraging ground. Chelonian Conserv Biol 8:1-10

Blumenthal JM, Austin TJ, Bothwell JB, Broderick AC and others (2009b) Diving behavior and movements of juvenile hawksbill turtles Eretmochelys imbricata on a Caribbean coral reef. Coral Reefs 28:55-65

Bolten AB (1999) Techniques for measuring sea turtles. In: Eckert KA, Bjorndal KA, Abreu-Grobois FA, Donnelly M (eds) Research and management techniques for the conservation of sea turtles. IUCN/SSC Marine Turtle Specialist Group Publication 4, Washington, DC, p 110-114

> Boulon RH Jr (1994) Growth rates of wild juvenile hawksbill turtles, Eretmochelys imbricata, in St. Thomas, United States Virgin Islands. Copeia 1994(3):811-814

Braun-McNeill J, Epperly SP, Avens L, Snover ML, Taylor JC (2008) Growth rates of loggerhead sea turtles (Caretta caretta) from the Western North Atlantic. Herpetol Conserv Biol 3:273-281

Chaloupka MY, Limpus CJ (1997) Robust statistical modelling of hawksbill sea turtle growth rates (southern Great Barrier Reef). Mar Ecol Prog Ser 146:1-8

Chaloupka MY, Limpus CJ, Miller JD (2004) Green turtle somatic growth dynamics in a spatially disjunct Great Barrier Reef metapopulation. Coral Reefs 23:325-335

Coastal Zone Management Unit (2002) GIS base map of Barbados reefs. Government of Barbados, Ministry of Housing, Lands and the Environment

> Diez CE, van Dam RP (2002) Habitat effect on hawksbill turtle growth rates on feeding grounds at Mona and Monito Islands, Puerto Rico. Mar Ecol Prog Ser 234:301-309

Fahrmeir L, Lang S (2001) Bayesian inference for generalised additive mixed models based on Markov random field priors. Appl Stat 50:201-220 
Gibbons JW, Semlitsch RD, Greene JL, Schubauer JP (1981) Variation in age and size at maturity of the slider turtle (Pseudemys scripta). Am Nat 117:841-845

Hastie T, Tibshirani R (1993) Varying-coefficient models. J R Stat Soc B 55:757-796

Hill MS (1998) Spongivory on Caribbean reefs releases corals from competition with sponges. Oecologia 117:143-150

Horrocks JA, Vermeer LA, Krueger B, Coyne M, Schroeder BA, Balazs G (2001) Migration routes and destination characteristics of post-nesting hawksbill turtles satellitetracked from Barbados, West Indies. Chelonian Conserv Biol 4:107-114

Ihaka R, Gentleman R (1996) R: a language for data analysis and graphics. J Comput Graph Statist 5:299-314

IUCN (International Union for Conservation of Nature) (2010) The IUCN Red List of Threatened Species. Version 2010.4 www.iucnredlist.org (accessed December 28, 2010)

Kubis S, Chaloupka M, Ehrhart L, Bresette M (2009) Growth rates of juvenile green turtles Chelonia mydas from three ecologically distinct foraging habitats along the east central coast of Florida, USA. Mar Ecol Prog Ser 389:257-269

Léon Y, Bjorndal KA (2002) Selective feeding in the hawksbill turtle, an important predator in coral reef ecosystems. Mar Ecol Prog Ser 245:249-258

León Y, Diez C (1999) Population structure of hawksbill turtles on a foraging ground in the Dominican Republic. Chelonian Conserv Biol 3:230-236

Limpus CJ, Chaloupka MY (1997) Nonparametric regression modeling of green sea turtle growth rates (southern Great Barrier Reef). Mar Ecol Prog Ser 149:23-34

Limpus CJ, Reed PC (1985) The green turtle, Chelonia mydas, in Queensland; a preliminary description of the population structure in a coral reef feeding ground. In: Grigg G, Shine R, Ehmann H (eds) Biology of Australasian frogs and reptiles. Royal Society of New South Wales, Sydney, p 47-52

Meylan A (1988) Spongivory in hawksbill turtles: a diet of glass. Science 239:393-395

Mora C (2008) A clear human footprint in the coral reefs of the Caribbean. Proc Biol Sci 275:767-773

Mortimer JA, Donnelly M (2007) IUCN Red List status assess-

Editorial responsibility: Hans Heinrich Janssen,

Oldendorf/Luhe, Germany ment. Hawksbill turtle (Eretmochelys imbricata). IUCN/ SSC Marine Turtle Specialist Group, Washington, DC

Mortimer JA, Collie J, Jupiter T, Chapman R, Liljevik A, Betsy B (2003) Growth rates of immature hawksbills (Eretmochelys imbricata) at Aldabra Atoll, Seychelles (Western Indian Ocean). In: Seminoff JA (ed) Proceedings of the 22nd Annual Symposium on Sea Turtle Biology and Conservation. NOAA Technical Memorandum NMFS-SEFSC503. US Department of Commerce, Miami, FL, p 247-248

Oxenford HA, Roach R, Brathwaite A, Nurse L and others (2008) Quantitative observations of a major coral bleaching event in Barbados, Southeastern Caribbean. Clim Change 87:435-449

Pinheiro J, Bates D (2000) Mixed-effects models in S and S-PLUS. Springer, New York, NY

R Development Core Team (2008) R: a language and environment for statistical computing. R Foundation for Statistical Computing, Vienna

Ricker WE (1975) Computation and interpretation of biological statistics of fish populations. Bull Fish Res Board Can 191:1-382

Seminoff JA, Resendiz A, Nichols WJ, Jones TT (2002) Growth rates of wild green turtles (Chelonia mydas) at a temperate foraging area in the Gulf of California, Mexico. Copeia 2002:610-617

van Dam R, Diez C (1997) Diving behavior of immature hawksbill turtles (Eretmochelys imbricata) on the reefs of Mona Island, Puerto Rico. Coral Reefs 16:133-138

Whiting SD, Guinea ML (1998) A large population of slow growing hawksbills: preliminary results from a wild foraging population in Fog Bay, Northern Territory. In: Epperly SP, Braun J (eds) Proceedings of the 17th Annual Sea Turtle Symposium. NOAA Technical Memorandum MNFS-SEFSC-415. US Department of Commerce, Miami, FL, p 104-107

Witzell WN (1983) Synopsis of biological data on the hawksbill turtle Eretmochelys imbricata (Linnaeus, 1766). FAO Fisheries Synopsis No. 137. FAO, Rome

Wood SN (2006) Generalized additive models: an introduction with R. Chapman \& Hall/CRC, Boca Raton, FL

Submitted: October 1, 2009; Accepted: March 10, 2011

Proofs received from author(s): May 31, 2011 